\title{
Assessment of pilot water shut off in high water production wells: case study in sudan
}

\begin{abstract}
A severe problem in oil-producing reservoirs is water production. Some reservoirs naturally more likely to face it, fluids tend to flow in least resistance which, are often created by the heterogeneous nature of the rock. Although reservoirs that supported by active bottom water drive and the Oil Water Contact (OWC) moved up to touch the bottom of oil column resulting in high water production. The water should be controlled in order to sustain the oil rate. Chemical water shut-off is a technology which has been used to control excessive water production. Producing Well- 4 with high water cut, $94.5 \%$ average $\mathrm{W} / \mathrm{C}$ pilot project of chemical water shut-off using Akron-RK technology, which based on polymer effect to gelling the water, is deployed. Liquid rate decreased from 10,700 to 3,000 bbl/day. Water cut did not drop even when the Electrical Submersible Pump (ESP) ran at low and different frequencies. Analysis the water production and comparing with previous water trend behavior shows there is no change in production trend. Heterogeneity effect on chemical water shut off project must take more sensitive factors to ensure the success of the project. Suggesting that there is possibility, of high vertical permeability which cause re assessment of isotropy factor.
\end{abstract}

Keywords: chemical water shut off, water production, permeability
Volume 2 Issue I - 2017

\author{
Azza Hashim Abbas, Wan Rosli Wan \\ Sulaiman, Mohd Zaidi Jaafar \\ Department of Petroleum Engineering, Universiti Teknologi \\ Malaysia, Malaysia
}

\author{
Correspondence: Azza Hashim Abbas, Department of \\ Petroleum Engineering, Universiti Teknologi Malaysia, Malaysia, \\ Email azzahashim2008@gmail.com
}

Received: December 06, 2016 | Published: January 19, 2017
Abbreviations: OWC: oil water contact; FVF: formation volume factor; WOR: water oil ratio; SG: gas specific gravity; API: american petroleum institute gravity; PB: bubble point pressure; GOR: gas oil ratio; IOR: improve oil recovery; CWSO: chemical water shut off; WC: water cut

\section{Introduction}

As soon as oil extracted from underground formations, in most cases water also comes to the surface, and it is usually called produced water. The sources of produced water include injected water, formation water and Aquifers water which consider the most difficult source to manage. Produced water is problematic in handle and treat, water production is global issue in term of environment, economic, and technical problems. In the oil and gas industry technically water production associate with problem as: reducing the productive life of wells, severe operational problems such as corrosion, fines migration and hydrostatic loading. Economic studies found that, water handling second biggest expense after drilling infill wells and biggest compared to other individual services required to drill wells for sustain production. With respect to the environmental impact, treatment and discharge represents a major challenge. ${ }^{1}$ Improved oil recovery (IOR) methods are used to solve some problems faced oil reservoirs such as water production and pressure depletion. It is financial decision to carefully nominate the way of fixing problems, like selection re inject the water to reach the ultimate goal of zero water discharge or dispose water and chemical treatment.

\section{Water production}

Some petroleum reservoirs are characteristically bounded by aquifers in bottom or in edges, these reservoirs highly candidate for unexpected water breakthrough. Since oil or gas is extracted pressure life of reservoir change and decreasing because phenomena called pressure depletion. ${ }^{2}$ Pressure depletion allows the compressed water in the aquifers to expand in order to balance the pressure. Flowing water driving by gravity in the permeable zones known as thief zones. The second source of this largest waste stream is the water that naturally occurs in the shale beds that are traversed by the wellbore. Water breakthrough problems through the whole lifecycle of the well has no clear understanding of estimating time or the volume and production rate of produced water over time according to several reasons.

\section{Water shut off}

Since late 80 s overflow water started to be a huge concern for production engineers, the goal was to be effectively manage and optimize production and maximize reservoir recovery and minimize the water cut. ${ }^{3}$ From literature survey lifting cost report showed that high water cut well is exponentially increasing as percentage of water cut increased. Example explain that $95 \%$ of water cut in lifting one barrel of oil cost half price comparing to the same well if it reaches $98 \%$. Although water cut recent reports of eldest field in the has reached the $98 \%$.In order to increase profitability, oil companies are putting an effort to reduce water production by executing water shut-off treatments. ${ }^{4}$ In 2000, Schulmberger Company -Bill Bailey et.al- introduced oil field review that shows 40 billion dollars spent in dealing with unwanted water. ${ }^{5}$ In reservoir surveillance management there are two ways of doing water shut-offs treatments which are mechanically by using packer to isolate wet-zone or work over jobs resqueeze-cement or re perforate the producing layers to target the most proper portion. Water shut-off treatments using chemical which perform when mechanical water shut-off treatments are obviously inapplicable, when the reservoir reach it is critical depleted. Chemicals are more expensive than mechanical water shut-off treatments. The Polymer gel technology in hydrocarbon industry had its beginning from 1960s. The use of Polymer Gel is to reduce water front in the wellbore so oil production will increase. Polymer technique can 
yield a significant improvement in oil field depending on reservoir characteristics and production operation techniques used to deplete the reservoir. Treatment of injection and production wells with various gel polymer has been developed in the Arbuckle reservoir in central Kansas. ${ }^{6}$ The degree of heterogeneity of the reservoir play huge rule in increasing failing possibility. Research report that several organic and inorganically attempted to solve the permeability variation. Although, gels can be created for extensive range of temperatures and salinities. Gel polymer treatment test in labs by utilizing the already available chemicals to improve the results of controlling results in two side's logistical and economical view. The modification in labs point to increasing the polymer concentration or adding a second component to the polymer that can react with the polymer to form a diversion agent which can both be attractive options to improve the volumetric sweep efficiency. There is various water shut-off chemicals as shown in for near wellbore area and deep profile modification. The polymer system is injected as a solution to go through deeply in the reservoir and lower permeability in the near wellbore area. In the treated injection well, the gel is placed into the high permeability fractures. Several methods were presented in the literature to determine the gel polymer properties including the bottle testing method, sealed tube method, dynamic shear method and static shear method (viscometer). ${ }^{8-10}$ After suitable choice for the field appliance by injected solution can move up and down the outside well bore, to help also in fix poorly cemented high permeable sands. Cleaning in the well bore need to be done and preferable by jetting water or acid.

\section{Methods}

Chemical treatment is reasonably low-cost water shut-off method. The measurement of effective successful job influences by different factors as: reservoir heterogeneity, the chosen of polymer, the selection of injection steps, amount and rate and how gel behaves in the reservoir. In order to judge the success of selected chemical in large scale, comparison between water production before and after production, reviewing procedures of chemical shut off need to be done. To justify the chemical job constraint, permeability checked to avoid the future undesired result. The principle used in this study consisted of analyzing the collected data: well test, logs, core, Production logs, history data for completion and work over. Reviewing the core sample record, project report, reservoir history and geological aspects. Although accurate near well model is required to simulate production of the well and effects of chemical treatment in the near well bore. The shut-off treatments target the near well area, a clear understanding of the near well reservoir characteristics and phenomena is critical for the successful design and implementation of the treatment.

In assessment of the pilot test was defined base on the methodology to complete properly evaluating the results. Reservoir description of the near well region is very important and all available.

\section{Field data}

The Heglig field is located on a highly oriented structure in the South East of the Muglad Basin. It is the largest commercial oil discovery in North Sudan. It was explored by Chevron in 1999. The seismic analysis shows the presence of rotated fault blocks which is surrounded by sub-basin structural lows. Heglig field area lies at depths of between 2 and $4 \mathrm{~km}$ where the oil and gas are discovered in Abu Gabra formation. The neighboring Fields share a similar temperature gradient which is about 3.5 (degree/100m). Layers temperatures have lateral drift across faults (rise from NE to SW). Source rocks (lacustrine) in the Sharaf and Abu Gabra formations Baraka, Nayil and Tendi shales. Oil properties in Sharaf and Abu Gabra are characterized by a low gas/oil ratio, low sulfur, high pour point, and high wax content. Well -4 was drilled in 1999 and completed excellently to target reservoir (bentiu-3).

\section{Core analysis}

Core samples were taken from the Bentiu-3. Core results show that main deposit character was Meandering sandstones with pebbles, poorly sorted, lamination depends on flow regime in bentiu 3. Petrophysical data for Bentiu-3 reservoir show a 0.538 Lorenz coefficient, which is almost a moderate heterogeneity. The 0.04 anisotropy factor is very small compared to the company cutoff. Porosity cut off is $12.6 \%$ and Saturation cut-off is $67.5 \%$. PVT analysis results from Formation Multi Tester (FMT) are determined as shown in Table 1

\section{Production results}

The First production started in 1999 making 1364bbl oil production with $70 \mathrm{bbl}$ water. By the end of the year, an electrical submersible pump started to be used. Table 2 shows the comparison between the production in 2011 and that in 1999.

Table I PVT Lab Results

\begin{tabular}{llllllllll}
\hline Formation & ${ }^{\circ} \mathbf{A P I}$ & FVF & Res T, ${ }^{\circ} \mathbf{C}$ & $\begin{array}{l}\text { Oil } \\
\text { viscosity }\end{array}$ & $\begin{array}{l}\text { Gas } \\
\text { SG }\end{array}$ & $\begin{array}{l}\text { GOR Scf/ } \\
\text { Stb }\end{array}$ & $\begin{array}{l}\text { Pb, } \\
\text { Psia }\end{array}$ & $\begin{array}{l}\text { Oil } \\
\text { density, } \\
\text { G/Cm3 }\end{array}$ \\
\hline Bentiu- 3 & 34.3 & 1.06 & 88.5 & 5.6 & 1.04 & 3.9 & 90.7 & 0.802 & $\begin{array}{l}\text { Assumed reservoir } \\
\text { pressure, Psia }\end{array}$ \\
\hline
\end{tabular}

Table 2 Results Production history

\begin{tabular}{|c|c|c|c|c|c|c|c|c|c|}
\hline Year & Month & Structure & Well & $\begin{array}{l}\text { Calendar oil } \\
\text { bpd }\end{array}$ & $\begin{array}{l}\text { Calendar } \\
\text { water bpd }\end{array}$ & Calendar & $\begin{array}{l}\text { Produced } \\
\text { oil bpd }\end{array}$ & $\begin{array}{l}\text { Produced } \\
\text { water bpd }\end{array}$ & $\begin{array}{l}\text { Produced } \\
\text { liquid bpd }\end{array}$ \\
\hline & & & & & & $\begin{array}{l}\text { liquid } \\
\text { bpd }\end{array}$ & & & \\
\hline 1999 & Jun & Heglig & 4 & 561 & 39 & 590 & 1364 & 70 & 1434 \\
\hline
\end{tabular}




\section{Pilot chemical procedure review}

Heglig field carried out this pilot test to determine the possibility Table 3 of water cut reduction. Review water shut-off Technology, that include inject polymer agents, depend on precise calculation for certain factors such as reaction and mixing coefficient (mass transfer rate). Comparing recorded production of oil and water after injection. Pre-test calculation shows injected amount is around $38 \mathrm{~m}^{\wedge} 3$ into the lower part which is closed to OWC. HE-04 Injectivity Test was successful and meeting the requirement. As shown in Figure 1. Shows the trend of oil and water can determine the problem is not only chemical chosen by the company.

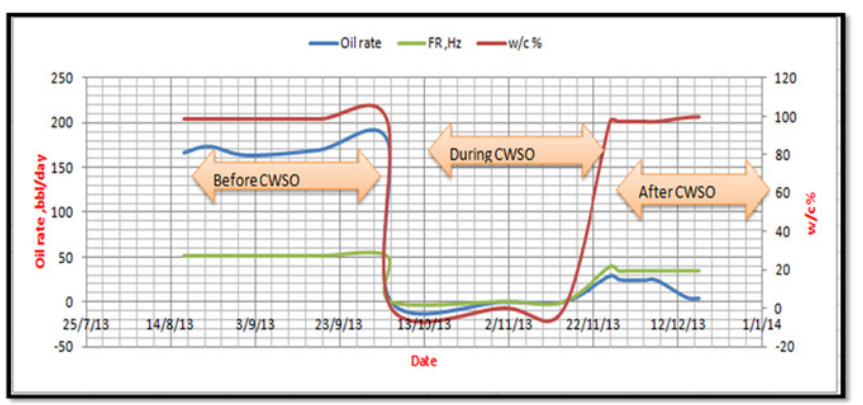

Figure I Oil Rate Relation with Pilot CWSO.

Table 3 Injectivity Test

\begin{tabular}{ll}
\hline Pressure psi & Injectivity bb/min \\
\hline 0.25 & 750 \\
0.25 & 800 \\
0.35 & 1000 \\
1.4 & 1250 \\
\hline
\end{tabular}

\section{Results and discussion}

The Used Chemical in the pilot was not sufficient to control the water contribution from lower zone of Bentiu-3. This might happen due to several reasons.

The new technology testing was carried out in four functional setup of the pulser letting to perform technological fluids injections into Bentiu-3 in pulse mode. The concept of the AKRON-RK technology composition is to penetrate the formation to create a strong barrier against formation water that withstands for a long time. In both around the perforations zone perimeter and in all water bearing strata zone, the resulted substance solidness is controllable (it could be like a stone or gum) according to the job requirements. Well-04 shows good Injectivity although the total planned chemical volume injected. The well water cut is still very high (around 98.5\%) and oil rate reduces rapidly till $60 \mathrm{bbl} / \mathrm{day}$.

In the high support water drive mechanism (edge aquifer), several points should be considered to use two different techniques for the same chemical pulse and continues. It should be noticed that the vertical permeability value larger than the horizontal permeability. Although that the anisotropy was neglected it may concern in this case it better to consider it again. Additional point from geology and structure, wells which are located at the higher structure have more probability than other wells to success. Wells perforation interval located above COWC better in selection criteria. Information of water cumulative production map will help identifying the best water shutoff treatments candidate.

\section{Conclusion}

Regular chemical water shut off was applied in high water cut wells is a routine in the wells improvement. The technology's efficiency could be determining by comparison of producing the water amount after injected. Designed quantity of chemical was injected successfully, by monitoring water, noticeable reduction was observed during the operation. This attempt may have been completely fail to reduce water production for long term. It showed that one of the issues associated with the reservoir's diagnosis is the information inaccuracy regarding permeability. Well simulation models for near wellbore excessive study for shut-off treatment. Calibrated by well data and well production history these models assist in interpretation and evaluation of results from field trials.

\section{Acknowledgments}

I would thank Development Department in GNPOC for their cooperation.

\section{Conflict of interest}

The author declares no conflict of interest.

\section{References}

1. Hibbeler JC, Rae PJ. The Environmental Benefits of Reducing Unwanted Water Production. SPE Asia Pacific Health, Safety and Environment Conference and Exhibition. Society of Petroleum Engineers. Kuala Lumpur, Malaysia, 2005.

2. Sulaiman WRW, Hashim A. Cyclic Steam Stimulation Effect on Skin Factor Reviewed Case Study. Applied Mechanics and Materials. 2016;818:287-290.

3. Sparlin DD, Hagen R. Controlling water in producing operations:using polyacrylamide polymers. World Oil. 1984;199(1).

4. Permana D, Fakhrizal F, Nurwibowo M. Selection Criteria for Successful Water Shut-Off Treatment-Brown Field Success Story. SPE Asia Pacific Oil and Gas Conference and Exhibition. Society of Petroleum Engineers. Jakarta, Indonesia, 2013.

5. Bailey B, Crabtree M, Tyrie J, et al. Water control. Oilfield Review. 2000;12(1):30-51.

6. Lashari ZA, Memon A, Ansari U, et al. Simulating the Effects of Water Shut-off Treatment by Polymer Gel Injection. PAPG/SPE Pakistan section Annual Technical Conference. Society of Petroleum Engineers. Islamabad, Pakistan, 2014.

7. Willhite GP, Pancake RE. Controlling Water Production Using Gelled Polymer Systems. SPE Reservoir Evaluation \& Engineering. 2008;11(3):454-465.

8. Broseta D, Marquer O, Blin N, et al. Rheological screening of lowmolecular-weight polyacrylamide /chromium (III) acetate water shutoff gels. SPE/DOE Improved Oil Recovery Symposium. Society of Petroleum Engineers. Oklahoma, USA, 2000.

9. Lei G, Li L, Nasr El, et al. New gel aggregates for water shut-off treatments. SPE Improved Oil Recovery Symposium. Oklahoma: Society of Petroleum Engineers; 2010.

10. Simjoo M, Vafaie Sefti M, Dadvand Koohi A, et al. Polyacrylamide gel polymer as water shut-off system:preparation and investigation of physical and chemical properties in one of the Iranian oil reservoirs conditions. Iran J Chem Chem Eng. 2007;26(4):99-108. 